\title{
Initial Lymphocyte Count and the Development of Persistent/Chronic Immune Thrombocytopenic Purpura
}

\author{
Ibrahim Ahmed, MD, DSc, ${ }^{1,2, *}$ Madhvi Rajpurkar, ${ }^{\text {MD }},{ }^{1}$ Ronald Thomas, $\mathrm{PhD}^{3}$ and Meera Chitlur, $\mathrm{MD}^{1, *}$
}

Background. Acute immune thrombocytopenic purpura (ITP) is a common, benign, self-limiting disease in children. Chronic ITP is diagnosed when thorombocytopenia persists beyond 12 months. Older age is associated with increased risk for development of chronic ITP. The main objective of the current study was to examine whether total leukocyte (TLC) and absolute lymphocyte counts (ALC) at diagnosis correlate with the persistence of ITP beyond 6 months. Procedure. Two hundred and twenty four consecutive medical records for patients diagnosed with immune thrombocytopenia, between April 1993 and July 2007, were reviewed and 188 patients were eligible for analysis. Case records were examined to ascertain the following information: age, gender, ethnicity, date of presentation, presenting $\mathrm{CBC}$ with differential count, treatment given and the outcome. Results. The male to female ratio was almost $1: 1 ; 24 \%$ (45/188) of patients had persistent ITP beyond 6 months. We determined that age $>8.5$ year, $\operatorname{TLC}<6,250 / \mu l$ and $\mathrm{ALC}<3,050 / \mu$ l was associated with a significant risk for development of persistent ITP beyond 6 months. Conclusions. TLC and ALC at diagnosis are predictive variables for the development of persistent/chronic ITP. Further studies are recommended to confirm the current finding and to assess the underlying pathophysiology with the course of the ITP. Pediatr Blood Cancer 2010;55:508-511. (C) 2010 Wiley-Liss, Inc.

Key words: hematology; immune cytopenias; immune thrombocytopenia; ITP; platelet disorders; thrombocytopenia

\section{INTRODUCTION}

Immune thrombocytopenic purpura (ITP) is an acquired autoimmune disorder characterized by increased platelet destruction and decreased platelet number [1,2]. Acute ITP is usually a benign, self-limiting disease, most commonly seen in children, and with an incidence of 4.0-5.3 per 100,000 per year [3-5]. In contrast, chronic ITP is diagnosed when thorombocytopenia persists beyond 12 months in an otherwise healthy individual and has an incidence of 0.46 per 100,000 children per year [6,7]. Older age, insidious onset and platelets count $>50,000 / \mu l$ at onset have been associated with increased risk for development of chronic ITP [8,9]. Differential white-cell counts at presentation have seldom been evaluated as predictors for the development of persistent ITP or chronic ITP. The main objective of the current study was to examine whether total leukocyte (TLC) and absolute lymphocyte counts (ALC) at diagnosis correlate with the course of the ITP.

\section{Patient Characteristics and Method}

In accordance with institutional IRB procedures, we conducted a retrospective cohort analysis of data from pediatric patients diagnosed with ITP at Children's Hospital of Michigan (CHM) — Wayne State University (WSU), Division of Pediatric Hematology and Oncology, from April 1993 to July 2007. The hospital electronic data base was used to obtain laboratory data such as the initial complete blood and differential counts, including total leukocyte, absolute lymphocyte, and platelet counts and absolute lymphocyte percent. In addition the medical records were reviewed for all patients diagnosed with ITP between December 1999 and July 2007.

Following validation of diagnoses, a total of 224 patients with ITP were identified. Thirty-six patients were excluded from the analysis, thirty for lack of follow-up data, and six for the lack of information on the initial complete blood counts at presentation before therapy is commenced. Thus, 188 patients diagnosed with ITP were included in the statistical analysis. Case records were examined to ascertain the following information: age, gender, ethnicity, date of presentation, presenting $\mathrm{CBC}$ with differential count, treatment given, and the outcome.

\section{Statistical Analysis}

Univariate statistical comparisons between the two study groups were conducted using a non-parametric Fisher's Exact Chi-square test for proportional differences. Where dependent variables were continuously scaled, either a parametric independent samples $t$-test was performed, if assumptions of normality and/or homogeneity of variance held, or if violated a non-parametric Mann-Whitney $U$ test. Receiver Operating Characteristic (ROC) curves were utilized to examine the strength of the prediction method in comparison to a yield point in the upper left corner or coordinate $(0,1)$ of the ROC space, representing $100 \%$ sensitivity (all true positives are found) and $100 \%$ specificity (no false positives are found). The best possible cutoffs points for chronic ITP were obtained, based upon the sample data, to guide diagnostic decision making.

\section{RESULTS}

One hundred eighty eight patients were eligible for analysis. Table I shows the demographic features for the study groups. Fortynine percent (92/188) were male and 51\% (96/188) were female.

\footnotetext{
${ }^{1}$ The Carman and Ann Adams Department of Pediatrics, Pediatric Hematology/Oncology Division, Children's Hospital of Michigan, Wayne State University, Detroit, Michigan; ${ }^{2}$ Pediatric Oncology Division, National Cancer Institute, Cairo University, Cairo, Egypt; ${ }^{3}$ Children's Research Center of Michigan, Wayne State University, Detroit, Michigan
}

Conflict of Interest: There are no affiliations that we consider to be relevant and important with any organization that to any author's knowledge has a direct interest, particularly a financial interest, in relation to the submitted manuscript.

*Correspondence to: Meera Chitlur, Children's Hospital of Michigan, Pediatric Hematology Oncology Division, 3901 Beaubien Blvd, Detroit, MI 48201. E-mail: mchitlur@dmc.org,cb_meera@hotmail.com

*Correspondence to: Ibrahim Ahmed, Pediatric Oncology Division, National Cancer Institute, Cairo University, Foum El-Khalig, Kasr AlAini, Cairo, Egypt. E-mail: ibradoc@gmail.com

Received 5 September 2009; Accepted 15 March 2010 
TABLE I. Demographic Features

\begin{tabular}{|c|c|c|c|c|c|c|}
\hline & \multicolumn{2}{|c|}{ Recovered ITP in less than 6 months } & \multicolumn{2}{|c|}{ Persistent more than 6 months ITP } & \multicolumn{2}{|c|}{ Total } \\
\hline & $\mathrm{N}$ & $\%$ & $\mathrm{~N}$ & $\%$ & $\mathrm{~N}$ & $\%$ \\
\hline \multicolumn{7}{|l|}{ Age } \\
\hline 0-11 months & 12 & 6.4 & 0 & 0 & 12 & 6.4 \\
\hline $1-10$ years & 110 & 58.5 & 26 & 13.8 & 136 & 72.3 \\
\hline $11-18$ years & 21 & 11.2 & 19 & 10.1 & 40 & 21.3 \\
\hline \multicolumn{7}{|l|}{ Race } \\
\hline Caucasian & 78 & 41.5 & 26 & 13.8 & 104 & 55.3 \\
\hline African American & 34 & 18.1 & 13 & 6.9 & 47 & 25.0 \\
\hline Hispanic & 8 & 4.3 & 1 & 0.5 & 9 & 4.8 \\
\hline Asian & 8 & 4.3 & 1 & 0.5 & 9 & 4.8 \\
\hline Middle Eastern & 11 & 5.9 & 3 & 1.6 & 14 & 7.4 \\
\hline Other & 4 & 2.1 & 1 & 0.5 & 5 & 2.7 \\
\hline \multicolumn{7}{|l|}{ Gender } \\
\hline Male & 70 & 37 & 22 & 12 & 92 & 49 \\
\hline Female & 73 & 39 & 23 & 12 & 96 & 51 \\
\hline Total & 143 & 76 & 45 & 24 & 188 & 100 \\
\hline
\end{tabular}

One hundred forty-three of 188 patients (76\%) were classified as belonging to Group I, in whom the ITP recovered within the first 6 months from date of diagnosis. Group II (45/188 or $24 \%$ ) constitutes patients in whom ITP lasted beyond 6 months from diagnosis. There was no statistically significant difference in the gender distribution of patients in each of these groups. The majority of the patients were Caucasian $(55 \%, 104 / 188)$, followed by African American $(25 \%$, $47 / 188$ ) respectively. The mean age at presentation of 6 years, standard deviation (SD) of 4.5 years and median of 4.4 years respectively, (min. 3 months max. 18 years) (Table I).

ITP lasting $>6$ months, (Group II) was associated with older age. The mean age was 8.5 years in Group II versus 6 years in Group I $(P=0.0001)$. All infants $<1$ year of age $(12 / 12$ patients $)$ had complete recovery of the platelet counts within the first 6-month period. A Seasonal trend was observed, with $60 \%$ (112/188) of newly diagnosed ITP patients presenting during the Winter/Spring seasons. Thirty-two patients had persistent thrombocytopenia at 6 months $(P=0.08)$.

Platelet count at presentation ranged from a low of zero to a high of $134,000 / \mu 1$. The mean presenting platelet counts for group I and group II were $15,420 \pm 22.6 / \mu 1$ and $22,040 \pm 27.4 / \mu 1$ respectively. Based upon univariate analysis, mean values of TLC, ALC and lymphocyte percentage were found to be significantly different between the study groups (Table II). The non-parametric multivariate analysis showed that a low TLC $(P \leq 0.001)$, ALC $(P<0.001)$, and lymphocyte percentage $(P=0.016)$ at presentation was associated with an increased risk for development of persistent ITP beyond 6 months. Application of the ROC analysis confirmed that lower TLC, ALC and lymphocyte percentage at presentation were helpful in predicting the persistence of ITP beyond 6 months (Fig. 1). Group II was associated with $\mathrm{TLC}<6,250 / \mu \mathrm{l}$, and $\mathrm{ALC}<3,050 / \mu$ l with lymphocyte percentage less than $50 \%$ at presentation. The TLC cut-off value sensitivity was $49 \%$, specificity was $77 \%$, positive predictive value (PPV) and negative predictive value (NPV) were $40 \%$ and $83 \%$ respectively; The ALC cut-off value sensitivity was $69 \%$, specificity was $66 \%$, PPV and NPV values were $39 \%$ and $87 \%$ respectively (Table III). Infants are known to have higher mean TLC and ALC values [10], Further analysis excluding the infant age group showed that the specific TLC and ALC cutoff values remained statistically significant when applied to the 1-18 years age group (Table IV). For the 1-18 years age group, the TLC cut-off value sensitivity was $49 \%$, specificity was $75 \%$, PPV and NPV were $40 \%$ and $81 \%$ respectively; The ALC selected cut-off value sensitivity was $69 \%$, specificity $62 \%$, PPV and NPV were $39 \%$ and $85 \%$ respectively.

Gender difference was not a confounding variable on any of the evaluated complete blood count parameters. Fifty percent (72/143) of patients in Group I and 76\% (34/45) of patients in Group II received some form of medical therapy other than watchful waiting and close follow-up. Only 4.4\% (2/45) of patients with group II had complete and sustained recovery of the platelet count within the first year; $95.6 \%$ of patients within group II (43/45) fulfilled the diagnosis of chronic ITP. Only $30 \%$ (13/43) patients with chronic ITP showed recovery on different time intervals beyond 1 year from diagnosis.

\section{DISCUSSION}

Twenty-four percent of our cohort group developed persistent ITP, 23\% developed chronic ITP, which corresponds to the reported data, with a range of $15-25 \%$ [5,11] developing chronic ITP. No gender preference was observed as reported by several epidemio-

TABLE II. Univariate Correlation Between ITP Outcome and the Mean Values of ALC, TLC, Lymphocyte\%, and Age

\begin{tabular}{|c|c|c|c|c|c|c|c|c|c|c|c|c|}
\hline & \multicolumn{3}{|c|}{$\operatorname{TLC}(\mathrm{n}=188)$} & \multicolumn{3}{|c|}{$\operatorname{ALC}(n=162)$} & \multicolumn{3}{|c|}{ Lymphocyte $(\%, \mathrm{n}=162)$} & \multicolumn{3}{|c|}{ Age $(n=188)$} \\
\hline & $\mathrm{N}$ & Mean (SD) & $P$ & $\mathrm{~N}$ & Mean (SD) & $P$ & $\mathrm{~N}$ & Mean (SD) & $P$ & $\mathrm{~N}$ & Mean (SD) & $P$ \\
\hline Group $\mathrm{I}^{\mathrm{a}}$ & 143 & $9.0(4.1)$ & 0.002 & 123 & $4.5(3.2)$ & $<0.001$ & 123 & $48(18)$ & 0.02 & 143 & $5.3(4.2)$ & 0.001 \\
\hline Group II $^{\mathrm{b}}$ & 45 & $6.9(3.0)$ & & 39 & $2.8(1.8)$ & & 39 & $40(14)$ & & 45 & $8.5(4.5)$ & \\
\hline
\end{tabular}

${ }^{\text {a }}$ Recovered ITP in less than 6 months; ${ }^{b}$ Persistent more than 6 months ITP. 

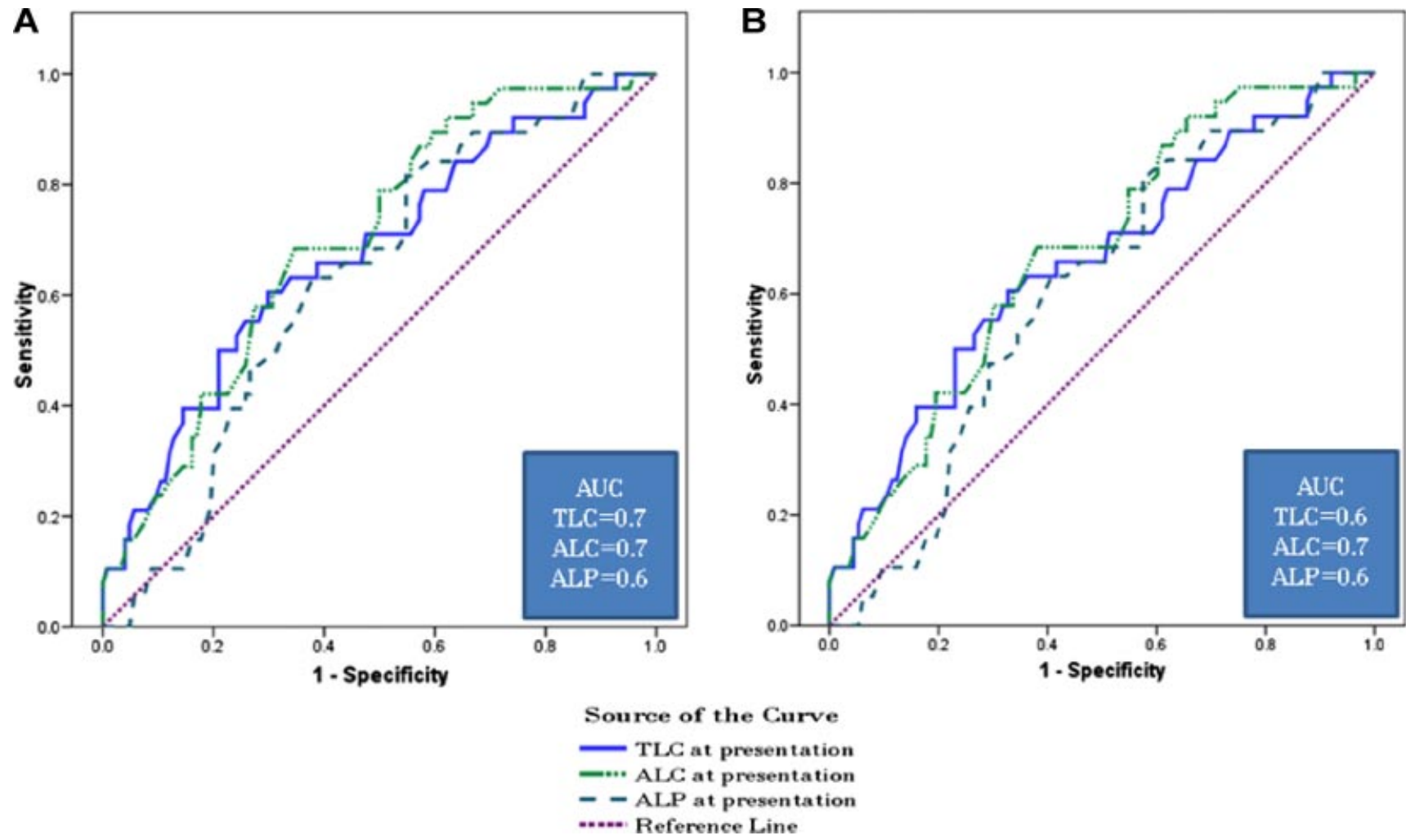

Fig. 1. ROC analysis revealed that lower TLC $(<6,250 / \mu 1), \operatorname{ALC}(<3,050 / \mu l)$ and lymphocyte percentage $(<50 \%)$ at presentation were helpful in predicting of persistent ITP beyond 6 months; ROC curve (A) represents all age groups and ROC curve (B) represents patients comprising group from 1 to 18 years. TLC, total leukocyte count; ALC, absolute lymphocyte count; ALP, absolute lymphocyte percent. [Color figure can be viewed in the online issue, which is available at www.interscience.wiley.com.]

TABLE III. Univariate Correlation Between ITP Outcome and Both the TLC and ALC Cutoff Variable

\begin{tabular}{|c|c|c|c|c|c|c|c|c|}
\hline & \multicolumn{4}{|c|}{$\operatorname{TLC}(\mathrm{n}=188)$} & \multicolumn{4}{|c|}{$\operatorname{ALC}(n=162)$} \\
\hline & $<6.25 \mathrm{k} / \mu \mathrm{l}$ & $>6.25 \mathrm{k} / \mu \mathrm{l}$ & OR $(95 \%$ CI $)$ & $P$ & $<3.050 \mathrm{k} / \mu \mathrm{l}$ & $>3.050 \mathrm{k} / \mu \mathrm{l}$ & OR $(95 \% \mathrm{CI})$ & $P$ \\
\hline Group I ${ }^{\mathrm{a}}$ & 33 & 110 & $0.31(0.16-.63)$ & 0.001 & 42 & 81 & $0.23(0.11-0.5)$ & $<0.0001$ \\
\hline Group II $^{\mathrm{b}}$ & 22 & 23 & & & 27 & 12 & & \\
\hline
\end{tabular}

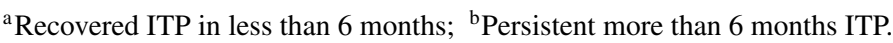

logic studies $[5,8,12-14]$, with no gender risk for the development of chronic ITP $[12,15]$.

In the current study, a younger cutoff age of 8.5 years was observed in association with the persistence of ITP beyond 6 months. A larger sample size is needed to assess the deviation from the previously reported cutoff age mean of 10 years for chronic ITP $[8,13]$. Furthermore, ethnicity did not contribute to that difference.

In the current study we could not support or refute what several studies reported regards the statistical significance of higher initial platelet counts in older patients and the incidence of chronic ITP due to small sample size $[8,9,13]$.

Culic et al. [16] observed an inverse correlation of ALC at diagnosis of ITP and platelet count in adult patients and suggested that a high ALC may be predictive of a poor prognosis in adult ITP patients; otherwise, total leukocyte, and absolute lymphocyte counts at presentation were seldom evaluated in pediatric patients with ITP.

Our data suggest that the development of persistent immune thrombocytopenic purpura was associated with TLC $<6,250 / \mu 1$,

TABLE IV. Correlation Between ITP Outcome and Both the TLC and ALC Cutoff Variable in Age Group 1-18 Years

\begin{tabular}{|c|c|c|c|c|c|c|c|c|}
\hline \multirow[b]{2}{*}{$1-18$ years age group } & \multicolumn{4}{|c|}{ TLC $(n=176)$} & \multicolumn{4}{|c|}{$\operatorname{ALC}(\mathrm{n}=151)$} \\
\hline & $<6.25 \mathrm{k} / \mu \mathrm{l}$ & $>6.25 \mathrm{k} / \mu \mathrm{l}$ & OR $(95 \% \mathrm{CI})$ & $P$ & $<3.05 \mathrm{k} / \mu \mathrm{l}$ & $>3.05 \mathrm{k} / \mu \mathrm{l}$ & OR $(95 \% \mathrm{CI})$ & $P$ \\
\hline Group I ${ }^{\mathrm{a}}$ & 33 & 98 & $0.35(0.17-0.71)$ & 0.005 & 42 & 70 & $0.27(0.12-0.58)$ & 0.001 \\
\hline Group II ${ }^{\mathrm{b}}$ & 22 & 23 & & & 27 & 12 & & \\
\hline
\end{tabular}

${ }^{\mathrm{a}}$ Recovered ITP in less than 6 months; ${ }^{\mathrm{b}}$ Persistent more than 6 months ITP. 
ALC $<3,050 / \mu l$ and with a negative predictive value of over $80 \%$. ALC is more sensitive than the TLC with a higher negative predictive value. Several studies have reported differences in the lymphocyte and natural killer cell repertoire, and defective circulatory CD25+ regulatory T-cells in association with ITP that could be related to the pathophysiological nature of the disease [17-21]. We suggest further prospective studies to evaluate the association of TLC and ALC and the underlying immune pathophysiology of ITP cohorts of patients.

Other than close observation, $56 \%$ of patients received specific medical treatment at presentation; the main reasons to treat were either the age of the patient at presentation and/or active bleeding. The patients were treated according to published recommendations and the American society of hematology (ASH) guidelines for treatment of childhood immune thrombocytopenic purpura [14,22,23]. Twenty-five percent of children with chronic ITP have been reported to show spontaneous recovery [24,25]. In the current report the platelet counts recovered in $33 \%$ of patients who had chronic ITP.

Our study indicates the possibility that acute and persistent/chronic ITP may represent two different immunopathological disorders. In light off the role of autoimmune component in the development of chronic ITP [26], further prospective studies may explain the association of low lymphocyte counts at presentation and persistent/chronic ITP.

In conclusion, our study showed that TLC and ALC are statistically strong predictors of the development of persistent/chronic ITP in pediatric patients. However, given the generally uncomplicated course of childhood ITP, many pediatricians may elect to manage children with ITP without referral to a hematologist. However, this study may provide a simple clue to pediatricians suggesting a need for referral to a hematologist if the initial ALC count is low. Confirmation of these results with larger studies would be recommended.

\section{ACKNOWLEDGMENTS}

Special acknowledgments to the late Patricia A. Fleming, RN for her support and contribution. Her meticulous tracking of these patients was instrumental for the completion of this study.

\section{REFERENCES}

1. Cooper N, Bussel J. The pathogenesis of immune thrombocytopaenic purpura. Br J Haematol 2006;133:364-374.

2. Kalpatthi R, Bussel JB. Diagnosis, pathophysiology and management of children with refractory immune thrombocytopenic purpura. Curr Opin Pediatr 2008;20:8-16.

3. Zeller B, Helgestad J, Hellebostad M, et al. Immune thrombocytopenic purpura in childhood in Norway: A prospective, populationbased registration. Pediatr Hematol Oncol 2000;17:551-558.

4. Lilleyman JS. Management of childhood idiopathic thrombocytopenic purpura. Br J Haematol 1999;105:871-875.

5. Zeller B, Rajantie J, Hedlund-Treutiger I, et al. Childhood idiopathic thrombocytopenic purpura in the Nordic countries: Epidemiology and predictors of chronic disease. Acta Paediatr 2005;94:178-184.

6. Reid MM. Chronic idiopathic thrombocytopenic purpura: Incidence, treatment, and outcome. Arch Dis Child 1995;72:125-128.

7. Rodeghiero F, Stasi R, Gernsheimer T, et al. Standardization of terminology, definitions and outcome criteria in immune thrombocytopenic purpura of adults and children: Report from an international working group. Blood 2009;113:2386-2393.
8. Glanz J, France E, Xu S, et al. A population-based, multisite cohort study of the predictors of chronic idiopathic thrombocytopenic purpura in children. Pediatrics 2008;121:e506-e512.

9. Watts RG. Idiopathic thrombocytopenic purpura: A 10-year natural history study at the childrens hospital of alabama. Clin Pediatr (Phila) 2004;43:691-702.

10. Nathan DG, Oski FA. Nathan and Oski's hematology of infancy and childhood, Vol.2. Philadelphia, PA: Saunders; 2003. xiv, 1864, xli p.

11. Guidelines for the investigation and management of idiopathic thrombocytopenic purpura in adults, children and in pregnancy. $\mathrm{Br}$ J Haematol 2003;120:574-596.

12. Fogarty PF, Segal JB. The epidemiology of immune thrombocytopenic purpura. Curr Opin Hematol 2007;14:515-519.

13. Kuhne T, Buchanan GR, Zimmerman S, et al. A prospective comparative study of 2540 infants and children with newly diagnosed idiopathic thrombocytopenic purpura (ITP) from the Intercontinental Childhood ITP Study Group. J Pediatr 2003;143:605608.

14. Tarantino M. Recent advances in the treatment of childhood immune thrombocytopenic purpura. Semin Hematol 2006;43:S11S17; discussionS18-S19.

15. Hedman A, Henter JI, Hedlund I, et al. Prevalence and treatment of chronic idiopathic thrombocytopenic purpura of childhood in Sweden. Acta Paediatr 1997;86:226-227.

16. Culic S, Labar B, Marusic A, et al. Correlations among age, cytokines, lymphocyte subtypes, and platelet counts in autoimmune thrombocytopenic purpura. Pediatr Blood Cancer 2006;47:671674.

17. Garcia-Suarez J, Prieto A, Reyes E, et al. Severe chronic autoimmune thrombocytopenic purpura is associated with an expansion of CD56+ CD3-natural killer cells subset. Blood 1993;82:15381545.

18. Gernsheimer T. Epidemiology and pathophysiology of immune thrombocytopenic purpura. Eur J Haematol Suppl 2008;3-8.

19. Stasi R, Cooper N, Del Poeta G, et al. Analysis of regulatory T-cell changes in patients with idiopathic thrombocytopenic purpura receiving $\mathrm{B}$ cell-depleting therapy with rituximab. Blood 2008;112:1147-1150.

20. Stasi R, Evangelista ML, Stipa E, et al. Idiopathic thrombocytopenic purpura: Current concepts in pathophysiology and management. Thromb Haemost 2008;99:4-13.

21. Yu J, Heck S, Patel V, et al. Defective circulating CD25 regulatory $\mathrm{T}$ cells in patients with chronic immune thrombocytopenic purpura. Blood 2008;112:1325-1328.

22. Beck CE, Nathan PC, Parkin PC, et al. Corticosteroids versus intravenous immune globulin for the treatment of acute immune thrombocytopenic purpura in children: A systematic review and meta-analysis of randomized controlled trials. J Pediatr 2005; 147:521-527.

23. George JN, Woolf SH, Raskob GE, et al. Idiopathic thrombocytopenic purpura: A practice guideline developed by explicit methods for the American Society of Hematology. Blood 1996;88:3-40.

24. Donato H, Picon A, Rapetti MC, et al. Splenectomy and spontaneous remission in children with chronic idiopathic thrombocytopenic purpura. Pediatr Blood Cancer 2006;47:737739 .

25. Imbach P, Kuhne T, Muller D, et al. Childhood ITP: 12 months follow-up data from the prospective registry I of the Intercontinental Childhood ITP Study Group (ICIS). Pediatr Blood Cancer 2006;46:351-356.

26. Gernsheimer T. Chronic idiopathic thrombocytopenic purpura: Mechanisms of pathogenesis. Oncologist 2009;14:12-21. 